\title{
Política de Ciência e Tecnologia no II PBDCT (1976)
}

Sergio Salles Filho

Professor do Departamento de Política Científica e Tecnológica/Instituto de Geociências/UNICAMP

No último número da Revista Brasileira de Inovação apresentamos excertos do I PBDCT com o intuito de mostrar como alguns temas referentes à interação entre ciência e tecnologia e o desenvolvimento nacional têm sido recorrentes no debate brasileiro nos últimos 30 anos. Não se trata apenas de apontar que temos tido dificuldades em resolver questôes já superadas em outros países, mas buscar explicações para esse descompasso, que é, sobretudo, de natureza organizacional e institucional. Três décadas de vaivém na inserção da ciência e da tecnologia na agenda política e econômica nacional devem servir como lição para, pelo menos, não cometermos os mesmos erros.

"Evitou-se, desde logo, a colocação de falsos dilemas. Pesquisa fundamental, pesquisa aplicada e inovação tecnológica têm de andar de braços dados. Senão, estaremos faltando ao bom senso e desperdiçando recursos públicos."

"Se vamos aplicar tantos bilhôes num plano como este, devemos assegurar relevância à ciência e tecnologia que se vai fazer na vida do País. Relevância em vários campos. Inicialmente, em termos de soluçôes tecnológicas para o atual estágio de desenvolvimento industrial e para a situação da crise de energia e os problemas de balanço de pagamentos - ou seja, a problemática relacionada com a nossa adaptação às novas condiçôes da economia mundial."

(trechos da apresentação do II PBDCT de João Paulo dos Reis Velloso ao Presidente da República) 
Originado na Secretaria de Planejamento da Presidência da República e elaborado com o suporte técnico do CNPq, foi publicado, em 5 de abril de 1976, o II Plano Básico de Desenvolvimento Científico e Tecnológico. O Decreto n. 77.355 de 31 de março de 1976 é assinado pelo Presidente da República e por dezessete Ministros de Estado.

Em sua estrutura, o II PBDCT tem quatro partes e dez capítulos. A primeira parte apresenta a política de C\&T do País; a segunda, os programas setoriais prioritários; a terceira parte a política de desenvolvimento científico e capacitação em pesquisa e a quarta e última parte fala sobre as atividades de suporte a C\&T.

Nesta apresentação são transcritos os capítulos I e IX.

Assim como no I PBDCT, havia neste Segundo Plano total aderência da política de C\&T à política nacional de desenvolvimento. O II PBDCT estava atrelado ao II Plano Nacional de Desenvolvimento. A necessária coerência já era visível àquela época. Aliás, antes disso. Como afirmam Guimarães \& Ford (1975) o Programa Estratégico de Desenvolvimento (PED) do período 1968 a 1970 "enfatizava a importância do desenvolvimento de pesquisas científicas e tecnológicas (...) Orientava-se pelos princípios de coordenação da ação governamental, execução descentralizada, concentração de recursos financeiros nacionais e estímulos à participação do setor privado".' Os autores ainda acrescentam: "Não que inexistisse, no Brasil, experiência anterior (mas a que houve...) se orientava, sobretudo, para a pesquisa científica, em estreita vinculação com os meios universitários e sem que se pensasse em articular tais atividades com as necessidades do sistema produtivo nacional" (Guimarães \& Ford, 1975:410-411). ${ }^{2}$

É neste sentido que a abertura do primeiro capítulo do II PBDCT, ao apresentar a política oficial de C\&T, enfatiza que os objetivos dessa política não podem ser "autonomamente definidos", mas devem ser derivados da estratégia de desenvolvimento adotada pelo País. Havia uma forte harmonia entre o planejamento maior do País e o planejamento em C\&T. Pelo menos no papel. Na verdade, era mais que uma harmonia, era uma vinculação, mas de uma só mão. O II PBDCT, diferentemente do primeiro, foi um plano de desenvolvimento tecnológico, no qual o Sistema Nacional de Desenvolvimento

\footnotetext{
Guimarães, E. A. A.; Ford, E. M., Ciência e Tecnologia nos Planos de Desenvolvimento: 1956/73. Rio de Janeiro, PPE, 5 (2), 1975.

2 Aliás, foi no PED que se apontou a necessidade de criação de um Plano Básico de Desenvolvimento Científico e Tecnológico.
} 
Científico e Tecnológico (SNDCT) deveria operar para as políticas industrial e agrícola. Todas as instituições assumiram, no Plano, um caráter funcional para o PND. O lado pesquisa científica perdeu importância em relação ao I PBDCT.

Em que pesem os princípios liberais que caracterizaram o discurso do II PND e o do II PBDCT, ${ }^{3}$ havia claramente uma proposição intervencionista que ia muito além da ação sobre as assim chamadas falhas de mercado. Naquele período, a política industrial possuía objetivos claros e métodos agressivos. Talvez por isso mesmo o enfoque tecnológico do II PBDCT tenha se acentuado em relação ao I PBDCT. Como se poderá constatar na seqüência desta seção "Memória", os capítulos relativos à tecnologia industrial e ao desenvolvimento agrícola não deixam dúvidas à filosofia do II PBDCT.

Mas mesmo considerando essa perspectiva, o II PBDCT não ignora o desenvolvimento científico nem tampouco a necessária ligação entre ciência, tecnologia e inovação. Isto fica claro no capítulo sobre organização institucional para o desenvolvimento científico e tecnológico. Repetia-se aqui a necessidade de ligação entre universidades e empresas e entre setores público e privado na geração e absorção de conhecimento. É explícita neste capítulo a necessidade de coordenação do SNDCT por parte de instituições já consolidadas, como o CNPq, e outras nascentes, como a Embrapa e a Embrater.

Assim, no mesmo espírito que propusemos no número anterior da Revista Brasileira de Inovação, esta seção procura dar seqüência à identificação de problemas e idéias recorrentes, para as quais não temos conseguido dar solução. A mobilização de diferentes atores do Sistema (hoje não mais sistema de C\&T, mas sistema de C,T\&I) e sua coordenação; a inserção do tema C,T\&I na agenda política do País; a intensificação das relações universidade-empresa e a maior participação do investimento privado, são temáticas com as quais nos debatemos há muito.

A epígrafe selecionada para esta introdução é reveladora. Já é passada a hora de repisarmos falsos dilemas como, por exemplo, o da briga estéril e anacrônica sobre a distinção de prioridades entre pesquisa básica, pesquisa aplicada e desenvolvimento experimental. O Manual Frascati foi e continua sendo útil, ${ }^{4}$

3 Expressões como "os princípios da economia de mercado devem guiar a ação do setor público" estavam presentes em ambos os Planos.

4 O Manual Frascati é uma publicação da OCDE que apresenta várias definições sobre pesquisa e desenvolvimento e propõe indicadores úteis para harmonizar e mensurar o "mundo da pesquisa". Está na quinta edição, sendo a primeira de 1963. Aliás, a última versão em português do Manual é de 1979, referente à edição de 1975. Já é hora de contarmos com a versão mais atualizada, que é de 1993. 
mas querer enquadrar as políticas de C\&T a partir de seus conceitos é, no mínimo, um erro de interpretação das funções do Manual. $^{5} \mathrm{O}$ avanço do conhecimento está estreitamente ligado às suas formas de apropriação e validação social. No longo prazo, a inovação não prescinde da ciência assim como a ciência não prescinde da inovação. Ainda que as rotas sejam complexas e muitas vezes imprevisíveis, as trajetórias de longo prazo são muito claras: o isolamento das partes compromete, por definição, os resultados do conjunto.

\section{Boa leitura!}

5 A "Família Frascati" progrediu e hoje conta com um conjunto de cinco manuais, dentre eles o de Oslo, base fundamental para a homogeneização de indicadores de inovação. A temática de C,T\&l evolviu muito e não há mais porque utilizarmos indicadores que pouco contribuem para o entendimento da realidade do desenvolvimento científico e tecnológico. 
Pronunciamento do Ministro Chefe da Secretaria de Planejamento da Presidência da República, JOÃO PAULO DOS REIS VELLOSO, na solenidade de lançamento do II Plano Básico de Desenvolvimento Científico e Tecnológico - PBDCT, em 31 de março de $1976^{*}$

O lançamento, pelo Governo de Vossa Excelência, Senhor Presidente, deste II PLANO BÁSICO DE DESENVOLVIMENTO CIENTÍFICO E TECNOLÓGICO (PBDCT), com dispêndios previstos, no período 1975/77, de quase Cr\$ 23 bilhões — preços de 1975 (isto é, o correspondente a US \$ 2,5 bilhões), significa, antes de tudo, que ciência e tecnologia são realmente coisa importante, no Brasil.

É só lembrar que o próprio PND previa aquele valor para período de 5 anos, até 1979 .

A média de dispêndios, no II PBDCT, é, pois, de Cr\$ 6,8 bilhões por ano. A do I PBDCT (também a preços de 1975) situou-se em Cr $\$ 3,8$ bilhões anuais. E em 1968 o programa de ciência e tecnologia era cerca de Cr\$ 200 a Cr\$ 300 milhões anuais (ainda a preços de 1975).

Vale lembrar que, em campo muito próximo, está sendo implementado, ainda, o Plano Nacional de Pós-Graduação, com aplicações, no período 1975/77, de Cr\$ 3,7 bilhões.

A orientação básica do II PBDCT é transformar a ciência e tecnologia em força motora do processo de desenvolvimento e modernização do País, industrial, econômica e socialmente. Trata-se, não de expandir um setor, mas de impulsionar uma nova fonte de dinamismo e transformação, a serviço dos objetivos da sociedade.

Evitou-se, desde logo, a colocação de falsos dilemas. Pesquisa fundamental, pesquisa aplicada e inovação tecnológica têm de andar de braços dados. Senão, estaremos faltando ao bom senso e desperdiçando recursos públicos.

Como assinala o II PND: “É necessário preservar o equilíbrio entre pesquisa fundamental, pesquisa aplicada e desenvolvimento, como estágios de um processo orgânico articulado com a economia e a sociedade".

O presente texto é uma reprodução fiel à publicação do II PBDCT da Presidência da República. 
No campo da tecnologia, evidentemente, em grande número de casos, trata-se de trazer tecnologia do exterior. Mas, mesmo aí, com a preocupação de, cada vez mais, aumentar o componente autônomo de adaptação e de elaboração própria, dentro da racionalidade econômica.

Há uma distinção a fazer entre a simples importação de tecnologia pronta, e a efetiva transferência de tecnologia, que, em diferentes gradações, conforme o caso (os conhecidos estágios da engenharia de fabricação, de produto e de processo), permite crescente autonomia interna, nos setores considerados prioritários para tal fim. É a velha história: a fórmula para manter um país subdesenvolvido é entregar-lhe sempre a tecnologia pronta e acabada.

Destina o II PBDCT, no período 1975/77, quase Cr\$3 bilhóes à área de Energia, Cr $\$ 6$ bilhões à Tecnologia Industrial, $\mathrm{Cr} \$ 3,1$ bilhões à Agropecuária, Cr\$ 1,7 bilhão ao Desenvolvimento Regional e Social, Cr\$ 800 milhões a Novas Tecnologias (fora da área de energia) e Cr\$ 440 milhões a outros setores de infra-estrutura. Para Desenvolvimento Científico e Formação de Recursos Humanos para a Pesquisa irão cerca de Cr\$ 6 bilhões.

Creio importante destacar dois pontos.

Primeiro: O Brasil está dando impulso ao desenvolvimento científico e tecnológico, em particular com um sistema de fundos e agentes especiais (FNDCT, FUNTEC, CNPq, FINEP, CAPES), que exercem, no setor, o papel que, por exemplo, o BNDE desempenha em relação às Indústrias Básicas.

Esse sistema financeiro e a expansão dos recursos dos Ministérios estão viabilizando a criação de condições adequadas de trabalho para o homem de pesquisa, além dos outros fatores que condicionam um clima geral favorável. "Máquinas ou prédios não fazem pesquisa, só o homem de primeira qualidade é quem a faz".

O segundo ponto é que, se vamos aplicar tantos bilhões num plano como este, devemos assegurar relevância à ciência e tecnologia que se vai fazer, na vida do País.

Relevância em vários campos.

Inicialmente, em termos de soluções tecnológicas para o atual estágio de desenvolvimento industrial e para a situação da crise de energia e os problemas de balanço de pagamentos — ou seja, a problemática relacionada com a nossa adaptação às novas condições da economia mundial. 
Aqui se coloca toda a temática do desenvolvimento da engenharia de produto e de processo, do desenvolvimento do "engineering" nacional e das associações entre empresas e instituições de pesquisas, ou destas duas com a universidade.

Evidentemente, no campo da energia, cabe grande destaque ao programa nuclear para fins pacíficos, com referência especial ao acordo com a República Federal da Alemanha.

No campo nuclear, é sabido que o Brasil irá desenvolver a Indústria de Reatores, com grau progressivo de nacionalização, além de todo o campo da tecnologia de combustíveis nucleares, inclusive para enriquecimento do urânio e tratamento de rejeitos radioativos.

Quanto a formas não convencionais de energia, o programa abrange desde aspectos relacionados com o curto prazo, como a mais ampla utilização do carvão nacional, inclusive para gaseificação, como aqueles de médio e longo prazo, como as aplicações da Energia Solar, principalmente no Nordeste (por exemplo, para uso de bombas para irrigação com água de subsolo), uso integrado do hidrogênio, como forma de energia e como matéria-prima industrial, e a fusão nuclear controlada.

Lembrem-se, também, em energia, os avanços na área de motores e turbinas para uso de álcool como combustível.

$\mathrm{Na}$ Área Industrial, projetos significativos se desenvolvem, hoje, para desenvolvimento de circuitos microeletrônicos, de que já resultou uma indústria brasileira de fabricação de dispositivos semicondutores, além do estabelecimento de dois grandes laboratórios universitários de microeletrônica. De tal esforço deverão sair os nossos computadores, segundo modelos próprios, e as centrais telefônicas, em etapa futura, semi-eletrônicas e totalmente eletrônicas.

Projetos, também, para construção de antenas para sistemas de microondas (com protótipos já realizados) e desenvolvimento de um sistema PCM de 30 canais telefônicos, entrando agora na fase de industrialização, além do início de elaboração de um novo sistema multiplex digital para 120 canais.

O outro campo diz respeito à exploração, por métodos nem sempre tradicionais, dos nossos recursos minerais e agropecuários, assim como o desafio representado, em termos ecológicos e econômicos, pelo Nordeste e pela Amazônia. 
É a tarefa de transformar recursos inertes em renda e emprego, desenvolvendo, em alto grau, a capacidade de pensar sobre os nossos próprios problemas de subcontinente tropical, de solo geologicamente antigo e, não raro, lixiviado.

Como pano de fundo para tal esforço, já podemos registrar que, graças ao projeto RADAMBRASIL, já somos, desde 15 de março, o País que possui o maior levantamento do mundo em imagens de radar, além do programa do INPE de levantamento de recursos terrestres mediante o emprego de imagens obtidas por satélites artificiais.

No tocante ao aproveitamento de recursos minerais, cabe citar os projetos relacionados com o caso do nióbio (abundante no Brasil) como elemento de adição na fundição de ligas não-ferrosas (em lugar do boro), com a metalurgia extrativa não convencional de zinco, com a metalurgia extrativa do níquel por processos não tradicionais de segregação, tendo em vista os minérios nacionais, com o lingotamento e fundição a vácuo do titânio metálico extraído de minério nacional, e com a eventual produção de fertilizantes fosfatados por via seca.

Quanto aos recursos agrícolas, além dos programas já realizados com referência a novas, consideravelmente mais produtivas, variedades de café, algodão, milho, cana-de-açúcar e arroz, merecem agora atenção especial as pesquisas relativas à soja, seja para diversificação de sua utilização industrial, seja para adição à farinha de trigo.

Poderemos acelerar a seleção de matrizes genéticas para melhoria vegetal através da "fertilização cruzada" de conhecimentos humanos, como o uso de ressonância paramagnética, para medir conteúdo em óleo, por exemplo, em sementes oleaginosas.

Ainda mais, com grande perspectiva para o futuro, devemos mencionar trabalhos científicos em desenvolvimento, na área de fixação assimbiótica de Nitrogênio atmosférico por bactérias de solo, em milho e cana, visando à redução de aplicação de adubos nitrogenados normalmente obtidos a partir do petróleo. Esse é um campo no qual estamos fazendo trabalho de vanguarda no mundo; seu sucesso permitirá uma grande economia de adubos nitrogenados, tão caros para nós.

O Programa do Trópico Úmido, para a Amazônia, e o Programa do Trópico Semi-Árido, para o Nordeste, já estão em curso. O primeiro, através 
do INPA, deverá preparar, nos próximos 5 anos, nada menos de 500 pesquisadores para atuar na área. O segundo se ocupa, particularmente, da agricultura seca (ou seja, sem irrigação) e do aproveitamento dos recursos das nossas matérias-primas vegetais: cera de carnaúba (celulose e papel), babaçu (coque siderúrgico, celulose e papel) etc.

O outro campo a que, finalmente, desejo referir-me é o das soluções para problemas de bem-estar social, em setores como Nutrição, Saúde, Saneamento e Educação.

Aqui, são, por exemplo, os projetos integrados concernentes a doenças tropicais, já também em pleno curso, quanto à esquistossomose, ao mal de Chagas, à malária e à leishmaniose.

Merece referência ao funcionamento de projetos de desenvolvimento de "know-how" nacional para a síntese de cerca de 20 produtos farmacêuticos atualmente importados em larga escala (inclusive insulina, sulfanilamida, ácido 6 - aminopenicilínico), além do projeto industrial de produção de ácido ascórbico (vitamina “C”).

\section{Senhor Presidente}

A presença, nesta solenidade, de vários Ministros e do Conselho TécnicoCientífico do CNPq me leva à palavra de conclusão, ressaltando, de um lado, o trabalho de equipe realizado, pelo Governo, na elaboração do II PBDCT, com a participação de todos os Ministérios e atuando o CNPq como órgão de coordenação do sistema. E de outro lado, a importância da participação, seja da empresa privada, seja da comunidade dos homens de ciência e tecnologia para o bom êxito do Plano.

Somos todos homens de trabalho, Governo e pesquisadores, com contas a prestar à sociedade.

Trabalhemos em cooperação, com objetividade e senso dos valores sociais e humanos da Nação que estamos construindo. 


\section{Capítulo I}

\section{O II PND e a Política de Ciência e Tecnologia}

\section{I.1. Ciência e tecnologia a serviço da sociedade}

Uma vez que uma política de ciência e tecnologia não define autonomamente seus objetivos mas antes os deriva da própria estratégia nacional de desenvolvimento, as diretrizes e proposiçôes contidas no plano científico e tecnológico para o período 1975/1979 resultam das necessidades de natureza científica e tecnológica decorrentes do projeto de desenvolvimento contido no II Plano Nacional de Desenvolvimento - PND, com vigência no mesmo qüinqüênio.

Sob esse aspecto, ressalte-se que as novas ênfases sublinhadas pelas diretrizes de política econômica contidas no II PND e os aperfeiçoamentos dos instrumentos e medidas mobilizados implicam em acentuar a importância do desenvolvimento científico e tecnológico para o cumprimento dos objetivos da estratégia nacional de desenvolvimento econômico e social.

$\mathrm{Na}$ verdade, do ponto de vista da maximização das taxas de crescimento no contexto da conjuntura da economia mundial dos últimos anos, o que se requeria era a continuidade do fluxo de conhecimentos tecnológicos para o sistema produtivo, independentemente da origem desse suprimento. Desta forma, os demais objetivos da política de ciência e tecnologia, ainda que articuláveis às diretrizes mais gerais de política econômica, não se apresentavam como indispensáveis à viabilidade do modelo brasileiro de crescimento.

Entretanto, a evolução das diretrizes de política econômica — ajustadas à nova etapa do processo de desenvolvimento do País e às mudanças ocorridas na economia mundial —, ao contemplar não só a correção das distorções e desbalanceamentos ainda existentes na estrutura produtiva e na distribuição da renda mas também a redução da dependência externa, estabelece, como requisitos para seu cumprimento, ademais da continuidade do fluxo de transferência de tecnologia externa, o avanço no processo de geração própria e significativa de conhecimentos técnicos, a par do uso consciente da ciência e da tecnologia na solução dos problemas específicos da realidade brasileira. 


\section{I.2. O contexto geral da política de ciência e tecnologia}

Vale destacar aqui alguns dos traços característicos da economia brasileira que, ao lado de condicionar os rumos mais gerais do processo de desenvolvimento, têm também reflexo direto na concepção da política científica e tecnológica do País. Caracterize-se, nesse sentido, a economia brasileira como tendo atingido um estágio avançado no processo de industrialização no qual se configurou um sistema econômico com participação de empresas públicas e de economia mista nas atividades produtivas e com a presença, não raro, do capital estrangeiro nos setores industriais mais dinâmicos. Como contrapartida, assinalem-se as condiçôes desfavoráveis de competitividade em que se encontra, freqüentemente, a empresa privada nacional.

As peculiaridades apontadas têm conseqüências importantes do ponto de vista da formulação da política de ciência e tecnologia.

De um lado, porque as condiçôes prevalecentes nas empresas nacionais privadas e a posição assumida pelas empresas estrangeiras podem constituir obstáculos ao desenvolvimento de uma tecnologia própria: seja porque as empresas nacionais não são, em geral, dotadas de capacidade financeira e gerencial e de estruturas administrativas que as habilitem a suportar, por si sós, atividades de pesquisa de maior significado, seja porque as empresas multinacionais podem não contemplar a realização de investigações mais complexas em suas subsidiárias em países de menor desenvolvimento.

De outro lado, a presença de entidades estatais no âmbito mesmo do sistema produtivo enseja formas diretas de atuação governamental na criação e na difusão de tecnologia no País. Indique-se, dentre essas formas, ao lado da realização de pesquisas tecnológicas pelas próprias empresas estatais, aquelas propiciadas pela posição dessas empresas como utilizadoras de máquinas, equipamentos e insumos e pela prática de associação com capitais privados, nacionais e estrangeiros, a que se tem crescentemente recorrido.

Embora tal configuração seja o resultado da própria dinâmica do processo brasileiro de desenvolvimento, postula-se como um objetivo de política econômica contrapor-se à tendência natural ao acentuamento dessas características, através do fortalecimento da empresa nacional. Tais intençôes se inserem no quadro das opções básicas da estratégia de desenvolvimento 
econômico proposta desde o I PND e contêm implicações significativas sobre a política científica e tecnológica.

\section{I.3. As opções básicas da estratégia econômica}

Convém examinar tais opções básicas e suas implicações. Elas incluem: a adoção de regime econômico de mercado, com ação norteadora e orientadora do setor público; a utilização de estruturas empresariais poderosas como forma de acelerar o desenvolvimento de certos setores; a decisão de absorver, complementarmente ao esforço interno, poupança, tecnologia e capacidade gerencial externas; o uso de tecnologia industrial moderna, como forma de adquirir poder de competição em grande número de setores industriais e de infra-estrutura; a incorporação à economia de mercado do grande espaço brasileiro; e a decisão de promover a melhoria da distribuição de renda e a abertura de oportunidades para todas as classes, realizando-as simultaneamente com a determinação de manter o crescimento acelerado.

Esta orientação implica preliminarmente em definir as funções a desempenhar e os setores para onde deverão destinar-se preferencialmente as empresas estatais e as multinacionais. As primeiras deverão concentrar-se nos setores de infra-estrutura ou participar daqueles projetos em que a sua presença viabilize o surgimento do empresário nacional em grandes empreendimentos. Quanto às multinacionais, ademais das funçôes de trazer de fato poupança externa e transferir tecnologia e capacidade empresarial, deseja-se ainda que venham a conquistar novos mercados pela expansão das exportações e a contribuir para o desenvolvimento da pesquisa no Brasil, devendo orientar-se, portanto, principalmente para setores em que possam assegurar aporte real de tecnologia avançada. Neste sentido, a empresa multinacional deverá ser induzida a destinar ao País parte dos seus gastos em pesquisa e desenvolvimento, através de orçamento próprio de pesquisa e da contratação de serviços de engenharia de projeto com empresas instaladas no Brasil.

Prevê-se ainda a criação de mecanismos capazes de dotar as empresas nacionais de condições razoáveis de competição em face da empresa estrangeira, através da correção das situações de debilidade daquelas empresas principalmente com relação a capital, financiamento de longo prazo, tecnologia e capacidade 
gerencial. Assim — ao lado da mobilização de medidas e instrumentos voltados para o aumento da capacitação financeira e administrativa dessas empresas e para a modernização dos processos produtivos utilizados, que se refletirão em maior demanda de tecnologia e no aumento do potencial de pesquisas das empresas nacionais (como a criação da IBRASA, ENBRAMEC e FIBASE, o programa Nacional de Treinamento de Executivos - PNTE, o Sistema CEBRAE - Centro Brasileiro de Assistência Gerencial à Pequena e Média Empresa, a ampliação da ação financiadora da FINEP e a utilização orientada do poder de compra das empresas governamentais) — a ação governamental deverá contemplar especificamente a intensificação do aporte interno de tecnologia para tais empresas e o acesso, em condiçôes favoráveis, a tecnologias somente disponíveis no exterior.

No que se refere ao fortalecimento da componente nacional da oferta de tecnologia, a ação governamental se traduzirá: no apoio à engenharia de projeto nacional, através, principalmente, da ação da Financiadora de Estudos e Projetos - FINEP junto às empresas nacionais de consultoria; na criação de incentivos para induzir a empresa nacional a realizar orçamento próprio de pesquisa; na promoção da implantação de centros de pesquisas nas empresas de maior porte ou através da associação de empresários; e no estabelecimento de canais que promovam a difusão, junto ao sistema empresarial, dos resultados das pesquisas realizadas por instituições governamentais.

Por outro lado, a política de transferência de tecnologia do exterior visará: à seleção da tecnologia a importar tendo em vista a sua importância para o desenvolvimento nacional e a possibilidade de solução interna do problema existente; ao melhor conhecimento da oferta mundial de tecnologia a fim de permitir ampla avaliação na escolha entre tecnologias alternativas, conferir maior poder de negociação às empresas nacionais e permitir avaliação adequada, pelo Governo, das importações feitas pela empresa estrangeira ou nacional; utilização flexível do sistema mundial de patentes; e remoção das restrições contratuais ou implícitas inconvenientes à economia nacional e que possam acompanhar os acordos de transferências.

O reconhecimento da necessidade do uso de tecnologias modernas, como forma de adquirir poder de competição em grande número de setores econômicos, não significa, porém, ignorar as implicaçóes de tal orientação 
quanto aos problemas do emprego, da distribuição da renda e da poluição do meio ambiente.

Neste sentido, caberá ter presente, sempre que possível, a adoção de soluções tecnológicas que não se oponham à política de expansão do emprego, o que, no entanto, não significa se aceite restringir o dinamismo da economia brasileira em nome daquele objetivo. Pelo contrário, entende-se que, no contexto mais geral do processo brasileiro de desenvolvimento, é justamente esse dinamismo que pode garantir a absorção progressiva da mão-de-obra subempregada no País.

Quanto aos problemas de poluição ambiental, contempla-se uma política de equilíbrio que concilie um elevado ritmo de crescimento com um mínimo de efeitos danosos sobre a ecologia e com o uso racional dos recursos naturais do País. As implicações, do ponto de vista da ciência e da tecnologia, da política de prevenção e combate à poluição consistem principalmente na preocupação com a adoção de técnicas produtivas de pequeno efeito poluidor e no desenvolvimento de tecnologia de controle da poluição nos setores mais importantes, bem como na implementação de programas específicos de pesquisas que busquem conhecer a situação ambiental, o comportamento e a quantidade de agentes poluentes no seio das comunidades e, ao mesmo tempo, procurem identificar a presença desses elementos nos principais rios e águas interiores, nas águas da costa e no ar atmosférico das regiōes metropolitanas, do mesmo modo que busquem a preservação dos recursos naturais renováveis.

Do ponto de vista do objetivo de incorporar à economia de mercado o grande espaço brasileiro, a política de integração nacional orienta-se principalmente no sentido de explorar a vocação do Brasil como supridor de produtos agrícolas. O esforço a ser empreendido para o desenvolvimento das regiōes Nordeste e Centro-Oeste e da Amazônia - utilizando o enfoque de áreas e programas integrados para permitir ação concentrada do Governo e do setor privado de modo a usufruir os benefícios de economias de escala, de economias externas e de economias de aglomeração — dependerá, de forma essencial, da aplicação da ciência e da tecnologia a regiôes tropicais tendo em vista melhorar o conhecimento das condições de adaptação do ser humano às peculiaridades dessas regiôes, bem como identificar as possibilidades produtivas dessas áreas e determinar tecnologias adequadas às especificidades regionais. São 
exemplos de iniciativas dessa natureza o Programa do Trópico Semi-Árido, o Programa do Trópico Úmido, o Projeto Aripuanã e o Programa de Cerrados.

Quanto à opção de melhorar a distribuição de renda e aumentar os padrôes de vida da população, além dos aspectos associados à política de emprego, são ainda significativas as implicações de natureza científica e tecnológica da diretriz de valorizar os recursos humanos e compensar a má distribuição de renda através de investimentos em educação, saúde e assistência médica, saneamento e nutrição. Com este propósito, será requerido: a realização de pesquisas referentes à medicina preventiva e ao controle e combate às doenças, notadamente as endêmicas; a capacitação do País para a produção de medicamentos e, em particular, de seus constituintes básicos; o desenvolvimento de programas de alimentação e nutrição, contemplando inclusive a realização de pesquisas científicas e tecnológicas nestas áreas e na da produção e industrialização de gêneros alimentícios essenciais; e o empreendimento de programas de tecnologia educacional tendentes a identificar métodos avançados de comunicação e ensino e ajuizar da sua aplicabilidade no Brasil.

Ao lado de derivar as implicações das diretrizes mais gerais do projeto nacional de desenvolvimento, cabe identificar também em que medida as estratégias setoriais do II PND contêm indicações quanto aos rumos a serem imprimidos aos programas e atividades que devem integrar o II PBDCT.

\subsection{A estratégia industrial}

A estratégia industrial contempla fundamentalmente realizar a configuração definitiva do perfil industrial que se deseja no Brasil, através de uma nova fase de substituição acelerada de importações sobretudo nos setores básicos - assegurando-se à empresa privada nacional papel importante neste processo de consolidação. Tal orientação visa a corrigir desbalanceamentos observados na estrutura industrial e desafogar o balanço de pagamentos em face dos desequilíbrios provocados pela nova conjuntura internacional.

Daí porque a ênfase da nova política industrial recai na indústria de bens de capital, na indústria eletrônica de base e na área de insumos básicos (produtos siderúrgicos, metais não-ferrosos, produtos petroquímicos, fertilizantes e defensivos agrícolas, papel e celulose, matérias-primas para a indústria 
farmacêutica, cimento e enxofre), segmentos em que se localizam as principais insuficiências da produção nacional e a maior parcela do ônus com a importação de manufaturados.

A mesma conjuntura internacional induz a que a estratégia industrial enfatize a abertura de novos campos de exportação de manufaturados, com maior complexidade tecnológica, em complemento às exportaçôes das indústrias tradicionais.

Tais indicaçôes da política industrial acarretam a expectativa de um acréscimo expressivo da demanda de tecnologia por parte do parque manufatureiro do País, não só porque, entre os fatores condicionantes das importações que se pretende substituir, destaca-se exatamente a carência de conhecimentos técnicos relativos a estes produtos e aos seus processos de fabricação, mas também porque a possibilidade de conquista de mercados para a produção nacional e a necessidade de evitar que as novas substituiçõos de importação se façam a custos excessivamente elevados, introduzem uma preocupação permanente com a eficiência da atividade produtiva e com a redução dos custos de produção.

A própria listagem dos setores a serem desenvolvidos prioritariamente e a relação dos produtos manufaturados cuja exportação é estimada no II PND constituem o indicador principal das ênfases que deverão ser conferidas pelo programa de desenvolvimento da tecnologia industrial.

Ao lado destes setores, aponte-se ainda: as indústrias tradicionais, a cujo processo de modernização e reorganização se pretende dar continuidade; a indústria de alimentos, cuja expansão tem conseqüências importantes do ponto de vista do objetivo de melhorar os padróes de vida da população; e os complexos agroindustriais que são chamados a desempenhar um papel relevante no desenvolvimento das regiōes mais atrasadas no País.

Evidentemente, a natureza das ações requeridas em cada um desses setores industriais é distinta. Em alguns casos, trata-se apenas da difusão de conhecimentos tecnológicos já existentes no País; em outros, da importação de conhecimentos técnicos, da sua absorção e da sua adaptação às especificidades nacionais; em outros ainda, da realização de pesquisas mais complexas e da criação de novas tecnologias como condição indispensável para a viabilização de determinadas atividades produtivas. 
Em todos os casos, mesmo quando a transferência de conhecimentos técnicos externos se apresenta como a solução mais viável e conveniente a curto prazo, como ocorrerá certamente na maioria das vezes, faz-se necessário que essa importação de tecnologia seja acompanhada de um esforço efetivo de assimilação interna, uma vez que esse processo de transferência não deve ser encarado apenas como uma maneira de superar obstáculos interpostos à expansão econômica do País, mas também como a aquisição de um insumo a ser elaborado e utilizado no processo de capacitação do País para a criação científica e tecnológica.

A posição peculiar que assume a indústria de bens de capital no contexto da política nacional de desenvolvimento da tecnologia industrial deve ser destacada. Em primeiro lugar porque aí, mais do que em qualquer outro setor, a importação de tecnologia é uma alternativa de eficácia limitada e substitui mal o domínio da engenharia de processo, de produto e de fabricação, notadamente no segmento produtor de bens de capital sob encomenda. De fato, parece situar-se nessa carência de conhecimentos técnicos um dos principais obstáculos a uma participação mais efetiva da indústria nacional no atendimento à demanda interna. Depois porque a indústria de bens de capital constitui-se em elemento estratégico para a difusão do progresso técnico no âmbito do sistema produtivo, uma vez que, como fornecedora de meios de produção para os demais setores de economia, este segmento recolhe solicitações de inovaçóes provenientes dessas fontes, e, ao incorporar o progresso técnico aos seus produtos, o difunde entre seus compradores.

Neste sentido, a promoção do desenvolvimento tecnológico da indústria de bens de capital, através do apoio à atividade de pesquisa e ao projetamento de engenharia de produto e fabricação, em complementaridade à importação e assimilação de conhecimentos técnicos, merece alta prioridade na política de tecnologia industrial.

Assinale-se, por fim, a necessidade de promover a complementação e consolidação de uma infra-estrutura tecnológica de suporte à atividade industrial, através de amplo programa de padronização industrial, compreendendo a metrologia, a normalização e o controle e certificação de qualidade; da modernização e consolidação do sistema de propriedade industrial; do estabelecimento de um sistema de informações tecnológicas voltado para as necessidades prioritárias do desenvolvimento industrial; e do fortalecimento da engenharia de projeto e de 
atividade de consultoria técnica no País. Além da importância das ações nestas direçôes para o processo de desenvolvimento industrial, notadamente no caso das iniciativas no campo da padronização industrial, vale destacar sua relevância do ponto de vista da diretriz de expandir as exportações de produtos manufaturados.

\section{I.5. A estratégia agropecuária}

No que diz respeito a estratégia agropecuária, espera-se maior contribuição do setor à expansão do Produto Interno Bruto, associada à redução de preços para o consumidor e à melhoria dos padróes de vida no campo, bem como à efetivação da vocação do Brasil como supridor de alimentos, matérias-primas agrícolas e produtos agrícolas industrializados.

Tendo em vista os requisitos para o cumprimento de tais objetivos — vale dizer, a utilização mais racional do solo e o estímulo a certa especialização que aproveite as vocações naturais de cada região; o incremento de produtividade através da modernização das práticas agrícolas e pecuárias e da mais ampla utilização de insumos modernos; a ocupação de novas áreas atenta à adequabilidade dos solos às novas culturas eà adoção de técnicas conservacionistas; e o desenvolvimento de complexos agroindustriais — é de se prever a necessidade de aporte significativo de conhecimentos científicos à atividade agropecuária.

A viabilização dessa estratégia dependerá, em boa medida, da dinamização do processo de criação e difusão de tecnologia adaptada às peculiaridades regionais. As possibilidades de contribuição de tecnologia importada são limitadas, não dispensando inclusive a realização de pesquisas que visem adequá-la às especificidades pedológicas e climáticas do País e de cada região.

As necessidades científicas e tecnológicas decorrentes da estratégia de desenvolvimento agropecuário compreendem, principalmente, pesquisas e estudos voltados para: o melhor conhecimento dos solos das diversas regiões e a identificação dos usos mais adequados, de modo a permitir o zoneamento ecológico e agrícola detalhado do País; o melhoramento genético e a identificação das variedades agrícolas mais adaptadas às várias condições ecológicas e climáticas; a definição de novas técnicas de cultivo, contemplando inclusive a melhoria das técnicas de conservação e de utilização do solo e a determinação dos fertilizantes compostos mais adequados aos diversos solos e culturas; a entomologia agrícola, o combate 
e a prevenção das pragas e a utilização de defensivos; a melhoria genética das espécies animais; a prevenção e o combate das moléstias e a produção veterinária; a melhoria da capacidade de suporte dos pastos; a identificação e a difusão de novos métodos de criação animal; e a fabricação de produtos de alimentação animal.

Contempla-se a formação de um novo modelo operacional para o setor público no tocante aos programas de pesquisa e experimentação agrícola (com programas regionais e por produtos perfeitamente definidos), bem como no tocante ao seu indispensável desdobramento, a extensão rural. Complementarmente à intensificação e à melhoria da atividade extensionista, pretende-se conferir à constituição de complexos agroindustriais um papel importante na difusão de novas tecnologias na produção agrícola. A inserção de núcleos dinâmicos e modernos — as grandes unidades agroindustriais — no âmbito da atividade agropecuária, deverá acarretar modificações significativas nos métodos e procedimentos do setor, seja pelo efeito de demonstração das lavouras geridas diretamente por aquelas unidades, seja porque tais empresas serão obrigadas a articular e a promover a modernização dos seus fornecedores de matérias-primas agrícolas.

O próprio desenvolvimento das agroindústrias requererá esforço expressivo de pesquisa, notadamente na área da engenharia de alimentos e na definição de processos de transformação industrial de produtos primários, mas também no âmbito mesmo da atividade agropecuária já que caberá identificar as variedades mais adaptadas ao processamento industrial e os métodos e técnicas de cultivo correspondentes, induzir à padronização da produção primária e introduzir no setor a preocupação com padróes mais rígidos de controle de qualidade.

Essa atenção à padronização e ao controle de qualidade não deverá restringirse à produção de matéria-prima para transformação industrial, uma vez que são requeridos avanços nessa direção também do ponto de vista de melhoria do sistema de armazenamento e de abastecimento e da defesa do consumidor.

\section{I.6. A política de energia}

No que se refere à política de energia, emerge como seu objetivo principal, no quadro resultante da elevação dos preços internacionais do 
petróleo, a redução da dependência em relação a fontes externas de energia. Esse objetivo será perseguido através de linhas de ação — aumento da oferta interna de petróleo, redução da demanda interna desse produto e diversificação das fontes internas de energia - que contêm implicações significativas para a atividade de pesquisa no País.

Quanto ao aumento da produção interna de petróleo, contempla-se implementar um programa maciço de prospecção e acelerar o programa de pesquisa para a utilização do xisto. Para reduzir o consumo interno de petróleo, ao lado da adoção de medidas de disciplinamento visando a evitar o desperdício, pretende-se promover a utilização de tecnologia poupadora de energia, principalmente na indústria e em setores de infra-estrutura, e também orientar a produção automobilística para modelos de reduzido consumo de combustível. No que diz respeito à diversificação das fontes internas de energia, ao mesmo tempo em que se aponta para a produção de álcool para adição à gasolina e para a ampliação do uso do carvão nacional para fins industriais, contempla-se desenvolver programa de pesquisa de fontes e formas não convencionais de energia, cuja amplitude e objetivos são destacados a seguir.

De resto, a execução do programa de energia elétrica e a ação programada no campo da energia nuclear se acrescentam às questôes anteriores como fatores de estímulo e como desafios à engenharia e à capacidade científica e tecnológica do País.

\section{I.7. Desenvolvimento de novas tecnologias}

Ao lado das indicações derivadas das opções básicas da estratégia de desenvolvimento e das políticas setoriais formuladas pelo II PND, ressalte-se a intenção de promover o desenvolvimento de novos campos tecnológicos, enfatizando-se, no próximo qüinqüênio, os programas de energia nuclear, de atividades espaciais, de recursos do mar, e de fontes e formas não-convencionais de energia.

Tais linhas de pesquisa, mesmo quando não diretamente vinculadas às atividades produtivas, ao menos a curto ou médio prazo, não esgotam sua justificativa na necessidade de acompanhar os avanços da ciência e tecnologia a nível mundial, mas são desejáveis também pelas conseqüências que podem 
acarretar para o processo de desenvolvimento econômico do País e para a melhoria dos padrôes de vida da população.

Além do caso da energia nuclear, onde a incorporação da nova tecnologia à atividade produtiva será um fato, neste qüinqüênio, são favoráveis as possibilidades de utilização dos resultados do programa de atividades espaciais através de serviços no campo de sensoreamento remoto dos recursos naturais em toda a sua vasta gama de aplicações, de comunicações e de serviços de meteorologia, bem como de aplicação de conhecimentos técnicos na aquacultura, na pesca, no aproveitamento da água do mar para produção de gelo e salmoura para uso industrial, na tecnologia do pescador e no reconhecimento e exploração econômica de reservas minerais da plataforma continental, que são esperados do programa de recursos do mar. Assinale-se ainda que a implementação de tais programas, em particular do programa de atividades espaciais, deverá estender seus efeitos à indústria nacional de bens de capital, uma vez que propiciarão o desenvolvimento de tecnologias e equipamentos cuja utilização não está restrita às atividades contempladas no programa.

Por fim, como já se assinalou, as crescentes necessidades energéticas do País e a escassez e custo crescente de combustíveis fósseis sugerem uma atenção redobrada na busca de mais possibilidades da utilização de fontes não convencionais e processos alternativos de obtenção de energia. Contempla-se o desenvolvimento de técnicas que permitam a produção de energia obtida de fontes não-poluidoras, e que tornem possíveis o transporte, armazenamento, distribuição e utilização desta energia, gerada com perspectivas econômicas favoráveis. A ação programada orienta-se principalmente para a economia do hidrogênio e para a energia solar, bem como para o acompanhamento, de forma sistemática, do esforço mundial nesta direção.

\section{I.8. Outras políticas setoriais}

Destaque-se, por fim, dentre os demais programas setoriais, os de transporte e de comunicações como os de maiores implicações do ponto de vista econômico e social e que oferecem, a par disto, oportunidades consideráveis para uma ação nacional própria de pesquisa e desenvolvimento experimental. 
No que se refere ao segundo, a expansão programada dos serviços públicos de telecomunicações e a dimensão relativa das instalações a serem implantadas em face das já existentes criam condições para que tais serviços venham se caracterizar pela utilização da tecnologia mais moderna, com o simultâneo fortalecimento empresarial e tecnológico da indústria brasileira.

Para que se viabilize, no entanto, uma contribuição mais efetiva da engenharia e da indústria nacionais no suprimento de tecnologia e dos equipamentos requeridos por esse programa, far-se-á necessário seja empreendido vigoroso esforço de pesquisas que objetivem soluções capazes de assegurar a obtenção de elementos materiais e a criação de sistemas e procedimentos adequados para a execução dos serviços de comunicações.

Desta forma, o programa de tecnologia na área de comunicações deverá orientar-se para a realização de pesquisa e de desenvolvimento, tendo em vista a criação de novas técnicas e/ou adaptação de tecnologias externas às peculiaridades do País e o desenvolvimento de protótipos de equipamentos. Caberá igualmente promover a transferência de novos conhecimentos técnicos a empresas nacionais e apoiar a produção interna dos equipamentos, materiais, componentes e sistemas requeridos para a expansão prevista da rede de comunicações.

Quanto à política de transporte, aponte-se a intenção de corrigir as distorções presentemente observadas na composição dos fluxos de carga, através do deslocamento progressivo do transporte de grandes massas para os setores ferroviário, marítimo e fluvial. Tal reorientação requererá, em particular, o fortalecimento e a modernização do sistema ferroviário, acarretando a necessidade de atualização tecnológica desse sistema. Essa diretriz deverá manifestar-se também no âmbito dos transportes urbanos, em relação aos quais deverão ser empreendidas iniciativas na área da pesquisa e desenvolvimento voltadas para a elaboração de novas soluções, ademais de esforço para manter atualizada a capacidade de absorção da tecnologia emergente em países mais avançados.

As iniciativas no campo dos transportes urbanos respondem também às indicações formuladas pelo II PND relativas à política de desenvolvimento urbano. As diretrizes concernentes a esta política apontam ainda a necessidade de empreender pesquisas específicas destinadas à busca de soluções para os problemas que afetam as regiões metropolitanas, notadamente no que concerne ao uso do solo, da habitação, do saneamento básico e da poluição ambiental. 


\section{I.9. Recursos humanos para ciência e tecnologia}

O esforço a ser realizado no próximo qüinqüênio para o desenvolvimento científico e tecnológico do País requererá mobilização igualmente intensa para a formação de recursos humanos.

Sob este aspecto, as exigências da economia e da sociedade brasileiras no tocante aos recursos humanos são, no presente, de natureza qualitativamente distinta da requerida nas etapas anteriores do processo de industrialização. $\mathrm{O}$ que se fazia necessário então era a formação de quadros técnicos capacitados para a operação do sistema produtivo. Tal nível de qualificação é evidentemente insuficiente quando se pretende aumentar a capacidade nacional de criação de tecnologia de modo a viabilizar maior grau de autonomia para o processo de desenvolvimento econômico do País.

Daí porque - sem que se descuide da formação de quadros técnicos, nos níveis médio e superior, na quantidade e na qualidade necessárias à operação do sistema produtivo - a ênfase da política de recursos humanos do II PBDCT se orienta para o desenvolvimento do ensino de pós-graduação. Através da execução do Plano Nacional de Pós-Graduação, conjugada principalmente com a atuação do CNPq, pretende-se integrar, na universidade, a pós-graduação e a pesquisa, preparando-se desta forma os recursos humanos para o desenvolvimento científico e tecnológico do País, ao mesmo tempo em que se consolida a estrutura institucional onde deverão se concentrar as atividades de pesquisa fundamental.

Caberá ainda proporcionar ao pesquisador e ao técnico de laboratório condiçôes de trabalho satisfatórias, contemplando-os inclusive com remuneração capaz de evitar sua transferência para outras atividades.

\section{I.10. Fortalecimento da empresa nacional}

A política científica e tecnológica, como preconizada no II PND, pretende que ciência e tecnologia, em sua dimensão mais ampla, devem servir aos objetivos gerais da sociedade brasileira, inclusive em seus aspectos sociais e humanos, na garantia da qualidade da vida, na defesa do patrimônio de recursos naturais do País. Ciência e tecnologia, no atual estágio da sociedade brasileira, representam 
uma força motora, o conduto, por excelência, da idéia de progresso e modernização.

É notório que a utilização do conhecimento científico sob a forma de progresso técnico no equacionamento de questões associadas ao bem-estar social, ou na ampliação e diversificação da produção de bens e serviços, como base do progresso material, guarda estreita dependência com a capacidade demonstrada por uma sociedade e seu sistema produtivo na geração e absorção de inovaçóes técnicas. No sentido mais amplo de progresso técnico e introdução de inovações identifica-se na empresa — pública ou privada - o agente dinâmico de tal processo. De outra parte, reconhece-se que o desenvolvimento de uma economia nacional só se materializa em ritmo e condições socialmente aceitáveis quando se apoia de modo preponderante nos seus próprios recursos - humanos, técnicos e de capital.

O cumprimento dos objetivos da política científica e tecnológica, e da própria política e estratégia de desenvolvimento econômico e social, fixados no II PND, está indissoluvelmente associado, portanto, ao êxito que se obtenha no programa de fortalecimento da Empresa Nacional, em particular da sua capacidade técnica.

O II PBDCT tem, por conseguinte, no desenvolvimento da qualificação tecnológica da Empresa Nacional — competência gerencial, eficiência na seleção e absorção de tecnologia e capacidade própria de "pesquisa e desenvolvimento" — uma diretriz fundamental.

O CNPq, como órgão coordenador do Sistema Nacional de Desenvolvimento Científico e Tecnológico, promoverá, diretamente e no âmbito de seu Conselho Científico e Tecnológico, as medidas de coordenação e orientação da atividade científica e tecnológica e estimulará a associação entre os organismos e empresas governamentais e o setor privado brasileiro, de tal modo que se beneficie efetivamente a Empresa Nacional dos resultados dos Planos Básicos aprovados pelo Governo Federal. 


\section{Capítulo IX}

\section{Organização Institucional para o Desenvolvimento Científico e Tecnológico}

Cabe indicar a estrutura institucional na qual se inserem a formulação e a implementação do II PBDCT, bem como os instrumentos de planejamento, fomento e financiamento disponíveis.

O programa de ação formulado pelo II PBDCTcontempla três grandes propósitos:

- ampliar a base nacional de recursos humanos qualificados para a operação do complexo ciência-tecnologia;

- utilizar o conhecimento científico e tecnológico disponível na solução dos problemas que afetam o desenvolvimento social;

- colocar os instrumentos gerados pela ciência e tecnologia à disposição do sistema produtivo nacional.

Neste sentido, na definição do quadro institucional e das formas de implementação da política de ciência e tecnologia, caberá ter presente, necessariamente, ademais da consolidação da estrutura interna do complexo científico e tecnológico, a articulação desse complexo ao sistema produtivo do País e aos organismos nacionais aos quais estão afetos a promoção do desenvolvimento social. Tal articulação deverá ensejar fluxos em duas direções: de um lado, deve criar canais de comunicação através dos quais o complexo científico e tecnológico seja alertado e sensibilizado para as necessidades concretas do desenvolvimento econômico e social do País; de outro, trata-se de garantir a rápida difusão e a utilização da produção científica e tecnológica do referido complexo. Da mesma forma, cumpre ter presente os vínculos entre os segmentos apontados — vale dizer, o complexo científico e tecnológico, o sistema produtivo e as entidades promotoras do desenvolvimento social - e o exterior, de modo a aumentar a contribuição externa não apenas ao desenvolvimento econômico e social da Nação mas ainda ao processo de progressiva capacitação nacional para a criação científica e tecnológica.

No tocante ao plano interno, o esforço de integração entre o complexo 
científico e tecnológico nacional e os setores potencialmente utilizadores de sua produção deverá desdobrar-se em dois níveis. Em um primeiro nível, trata-se de articulação a ser promovida no âmbito do setor público, aproximando a oferta interna de ciência e tecnologia à parcela da demanda que se explicita através desse mesmo setor e que compreende os conhecimentos científicos e tecnológicos requeridos pela execução de programas de desenvolvimento econômico e social de responsabilidade direta do Governo, bem como a tecnologia demandada pelas empresas estatais e de economia mista. Em um segundo nível, cabe articular a atuação das universidades e dos institutos de pesquisa, em geral situados na esfera dos Governos Federal e Estaduais, com as iniciativas do setor privado da economia.

Evidentemente, cada um destes níveis de articulação propõe questôes distintas e requer instrumentos e formas operacionais diferenciados. Em particular, salienta-se que a política científica e tecnológica, que tem caráter imperativo no caso das ações na esfera pública, é de natureza indicativa no que diz respeito à sua orientação ao setor privado.

Ressalte-se, de logo, que a sistemática de elaboração de Planos Básicos de Desenvolvimento Científico e Tecnológico, instituída pelo Decreto no 70 553/72, ganha força e amplitude com as transformaçóes operadas a partir de maio de 1974 no Sistema Federal de Planejamento, e do qual os referidos Planos constituem instrumentos de ordenação da atividade de pesquisas no âmbito do Setor Público, de coordenação das medidas de apoio ao desenvolvimento tecnológico da Empresa Nacional e de orientação geral para as iniciativas do Setor Privado nesse campo.

Com a aprovação da Lei no 6 036/74, introduziram-se modificaçóes na organização administrativa federal de grande significado para o planejamento econômico e social e, por decorrência, do desenvolvimento científico e tecnológico. Criou-se, então, na Presidência da República, como órgão de assessoramento direto do Presidente da República, a Secretaria de Planejamento-SEPLAN, que absorveu as atribuições do antigo Ministério do Planejamento e Coordenação Geral, inclusive a gestão dos Fundos por ele administrados.

Consoante o art. $7^{\circ}$ da Lei citada, à Secretaria de Planejamento incumbe, em particular assistir o Presidente da República na coordenação do sistema de planejamento, orçamento, reforma administrativa e das medidas relativas à política de desenvolvimento econômico e social. E, também, como reza o inciso III desse artigo: 
"III — Na coordenação da política de desenvolvimento científico e tecnológico, principalmente em seus aspectos econômico-financeiros, ressalvada a competência deferida à Secretaria-Geral do Conselho de Segurança Nacional”.

A fim de permitir a SEPLAN realizar efetiva coordenação da política de desenvolvimento científico e tecnológico, a mesma Lei no 6 036/74, colocou, sob a supervisão, o Conselho Nacional de Pesquisas-CNPq, em igual condição com o Banco Nacional de Desenvolvimento Econômico-BNDE, a Financiadora de Estudos e Projetos-FINEP, a Fundação Instituto de Planejamento Econômico e Social-IPEA e a Fundação Instituto Brasileiro de Geografia e Estatística-IBGE.

Como desdobramento das alteraçoos trazidas pela Lei no 6 036/74, buscou-se conferir ao CNPq, autarquia criada em 1951, a condição jurídica e legal e a capacidade técnico-administrativa necessárias ao cumprimento de funçōes que seriam consideravelmente ampliadas.

Com a sanção da Lei no 6 129/74, institui-se, como personalidade jurídica de direito privado, sob a forma de fundação, vinculada à SEPLAN, o Conselho Nacional de Desenvolvimento Científico e Tecnológico-CNPq, por transformação do antigo Conselho Nacional de Pesquisas. $\mathrm{O}$ art. $2^{\circ}$ estabelece:

"Art. 20 - O Conselho terá por finalidade auxiliar o Ministro de Estado Chefe da Secretaria de Planejamento no desempenho das atribuições que a este foram conferidas pelo artigo $7^{\circ}$, item III, da Lei $n^{\circ} 6036$, de $1^{\circ}$ de maio de 1974, principalmente quanto à análise de planos e programas setoriais de ciência e tecnologia e quanto à formulação e atualização da política de desenvolvimento científico e tecnológico, estabelecida pelo Governo Federal.

Parágrafo único — Para atender às suas finalidades, o CNPq poderá manter os Institutos subordinados ao Conselho Nacional de Pesquisas, bem como criar novos Institutos ou outros mecanismos".

Os Estatutos do Conselho, baixados com o Decreto no 75 241/75, explicitaram a competência do CNPq, em seu Art. $4^{\circ}$, na forma que segue: 
"Art. 4o - Compete ao CNPq, especialmente:

I - Auxiliar o Ministro Chefe da Secretaria de Planejamento na coordenação da elaboração do Plano Básico de Desenvolvimento Científico e Tecnológico-PBDCT e o acompanhamento de sua execução, assim como a análise de planos e programas setoriais de ciência e tecnologia.

II - Estimular a realização de programas e projetos de intercâmbio e transferência de tecnologia entre entidades públicas e privadas, nacionais, estrangeiras ou internacionais.

III - Promover a implantação de mecanismos de coleta, análise, armazenamento, difusão e intercâmbio de dados e informações sobre desenvolvimento científico e tecnológico.

IV - Participar do estudo de atos internacionais de interesse para o desenvolvimento científico e tecnológico.

$\mathrm{V}$ - Propor normas e instrumentos de apoio e estímulo às atividades de pesquisas científicas e tecnológicas de interesse do desenvolvimento econômico e social.

VI - Promover estudos e programas integrados de formação, avaliação e valorização de recursos humanos nas áreas de ciência e tecnologia.

VII - Promover, no País e no exterior, reuniōes de natureza científica e tecnológica ou delas participar.

VIII - Assistir financeiramente a pesquisa, com recursos a esse fim destinados.

IX — Prestar assistência técnica no campo de sua atuação".

É importante assinalar as características essenciais adquiridas pelo $\mathrm{CNPq}$ com tais transformaçôes:

- órgão auxiliar da SEPLAN na coordenação do programa de desenvolvimento científico e tecnológico, correspondendo-lhe, como missão básica, coordenar a elaboração do PBDCT e participar do estudo de atos internacionais de interesse para os objetivos e metas do Plano Básico;

- órgão de apoio direto à pesquisa, assistindo-a financeiramente com recursos a esse fim destinados;

- executor, por intermédio dos Institutos que lhe são subordinados e de 
outros que porventura venham a ser criados, de programas e atividades nos campos técnico-científicos que lhes são próprios.

O Conselho Científico e Tecnológico-CCT é o órgão máximo de aconselhamento do CNPq, com representatividade adequada, quer no plano político quer no plano científico e técnico. É integrado, com esse propósito, por trinta Conselheiros, dos quais quinze são membros natos e os demais, com mandatos de 2 anos, renováveis por um período, designados principalmente dentre cientistas, tecnólogos, pesquisadores, todos brasileiros e que desenvolvam atividades relevantes nos setores da Ciência ou da Tecnologia.

Complementando os atos de instituição e normativos da ação do CNPq, buscou-se equacionar convenientemente a articulação, ou integração, entre o complexo científico e tecnológico nacional e os setores potencialmente utilizadores de sua produção. Como se fez menção, de início, tal questão se coloca em dois níveis: a articulação a ser promovida no âmbito do setor público e a articulação entre as universidades e institutos de pesquisa governamentais e o setor privado nacional.

O problema, como colocado, encontra resolução institucional compatível no Sistema Nacional de Desenvolvimento Científico e Tecnológico-SNDCT, sobre o qual dispõe o Decreto no 75 225/75.

O Decreto no 75 225/75, em apreço, organiza as atividades da área de ciência e tecnologia sob a forma de sistema. Assim, determina que o Sistema Nacional de Desenvolvimento Científico e Tecnológico-SNDCT deverá dispor, nos Ministérios com atuação significativa na área, de Órgãos Setoriais, revestidos preferencialmente da forma de Secretarias de Tecnologia, responsáveis pela supervisão de todas as unidades organizacionais de qualquer grau dos respectivos Ministérios que realizem atividades de planejamento, supervisão, coordenação, estímulo, execução, ou controle de pesquisas científicas e tecnológicas, e pela sua utilização pelos setores econômicos e sociais.

Nesse contexto, o Plano Básico de Desenvolvimento Científico e Tecnológico aparece como instrumento de previsão, orientação e coordenação da ação integrada do SNDCT; sua elaboração, coordenada pela Secretaria de Planejamento com o auxílio do CNPq, resulta da análise e compatibilização dos planos e programas setoriais de ciência e tecnologia formulados pelos Órgãos 
Setoriais do SNDCT, com a progressiva incorporação das ações de outras esferas de Governo e com a associação crescente do setor privado ao esforço nacional em pesquisa.

O Conselho Nacional de Desenvolvimento Científico e Tecnológico-CNPq é o órgão de coordenação do SNDCT, devendo ainda promover a articulação com os Estados, Territórios, Distrito Federal e Municípios, visando à compatibilização de esforços.

O CNPq, por intermédio do seu Conselho Científico e Tecnológico, órgão colegiado, integrado pelos titulares dos Órgãos Setoriais do SNDCT previstos no Decreto n ${ }^{\circ} 72525 / 75$, e por representantes da comunidade científica e tecnológica nacional, constituirá o foro aprimorado à coordenação do Sistema, cabendo-lhe, como visto, opinar e fornecer subsídios à formulação da política de ciência e tecnologia, bem como cooperar na elaboração e no acompanhamento do PBDCT e de programas e projetos setoriais ou especiais de interesse. Em seu funcionamento, o Conselho Científico e Tecnológico-CCT se desdobrará em Comissões, que constituirão elemento de integração de diversos segmentos do complexo científico e tecnológico, e permitirão ainda articular este complexo com os setores utilizadores. Em outras palavras, buscando o ajustamento entre a oferta e a demanda de ciência e de tecnologia.

No que diz respeito à demanda de conhecimentos científicos e tecnológicos do setor público, vale dizer aquela requerida pelos programas de desenvolvimento social e pelas empresas públicas, a interação entre oferta e demanda no âmbito dessas Comissões é simplificada pela circunstância de que o CNPq, no seu órgão colegiado (CCT), reúne ambos os lados num mesmo plenário.

Quanto à articulação entre as entidades do complexo governamental de pesquisas e o setor privado, embora deva ter lugar também no âmbito do CNPq, será facilitada pela mediação prévia realizada por outros organismos. Aqui, cabe distinguir entre a tecnologia agrícola e a tecnologia industrial.

No primeiro caso, a existência de uma estrutura de pesquisas em vias de implantação segundo novo modelo institucional e que é relativamente centralizada, apresentando inclusive grau satisfatório de coordenação com sistemas estaduais de pesquisa e mecanismos próprios de difusão dos resultados de seus trabalhos, junto ao setor privado, implica em esforço adicional para complementar esse processo de articulação que tem na EMBRAPA e na 
EMBRATER, do Ministério da Agricultura, os seus entes principais. A partir daí, a coordenação superior do Sistema no âmbito do CNPq estará consideravelmente simplificada.

O caso da tecnologia industrial é inegavelmente mais complexo, em conseqüência, principalmente, do elevado número de instituições de pesquisas existentes, subordinadas a diferentes organismos governamentais e a diferentes níveis de governo e do amplo espectro de utilizações que caracteriza a tecnologia originária do setor industrial, afetando quase que a totalidade das atividades sociais, e de caráter produtivo.

O Sistema Nacional de Desenvolvimento Científico e TecnológicoSNDCT, como assinalado anteriormente, constitui solução institucional apropriada para a formulação e a implementação das diretrizes fixadas para o setor de tecnologia industrial. A convergência e a conciliação de interesses das fontes de tecnologia industrial e dos entes utilizadores da mesma, de tal modo que maximizem e se cumpram os objetivos e as ações previstas no II PBDCT e nos que lhe sucederem, demanda ampla participação dos diferentes setores governamentais e privados envolvidos nesse processo. É importante destacar, neste particular, como integrante do SNDCT, o papel da Secretaria de Tecnologia Industrial-STI, do Ministério da Indústria e do Comércio, no processo de elaboração e no cumprimento das referidas diretrizes, quer pelo contato estreito que deve manter com o órgão formulador da política industrial — o Conselho de Desenvolvimento Industrial-CDI - quer pela supervisão que lhe cabe de importantes instrumentos de orientação e apoio ao desenvolvimento e ao uso eficiente da tecnologia industrial — geração e utilização — de que são exemplos o Instituto Nacional de Tecnologia-INT, o Instituto Nacional de Metrologia, Normalização e Qualidade Industrial-INMETRO e o seu ConselhoCONMETRO e o Instituto Nacional de Propriedade Industrial-INPI.

No que diz respeito à aplicação de estímulos específicos ao desenvolvimento tecnológico industrial, em particular aqueles de natureza financeira, cumpre, em particular, coordenarem-se as ações da STI-MIC, do BNDE e da FINEP no plano de programas setoriais, com o uso apropriado das respectivas competências e vocações, competindo ao CNPq, como órgão central do SNDCT, promover tal coordenação, sempre que necessário.

No que concerne à FINEP, com os seus novos Estatutos aprovados pelo 
Decreto no 75 472/75, estará a empresa melhor habilitada ao desempenho de suas funções como entidade financiadora de programas e projetos de desenvolvimento econômico, social, científico e tecnológico, com ênfase na promoção do desenvolvimento tecnológico da Empresa Nacional, consoante linhas de ação já estabelecidas; como Secretaria Executiva do Fundo Nacional de Desenvolvimento Científico e Tecnológico FNDCT; e como principal agente financeiro do CNPq.

Convém ressaltar que o apoio ao desenvolvimento tecnológico propiciado pelo BNDE será ampliado com a expansão dos recursos sob sua administração direta e com o crescimento das atividades das empresas sob seu controle criadas, em 1974, para promover, mediante participação societária, o fortalecimento das indústrias de bens de capital (EMBRAMEC), de insumos básicos (FIBASE) e da empresa industrial nacional em geral (IBRASA). Como diretriz básica, o sistema financiador liderado pelo BNDE incorporará explicitamente às suas operaçôes a variável tecnológica, aplicando modalidades adequadas de crédito ou de associação no risco, compatíveis com os investimentos em pesquisa. Tais aplicações serão combinadas com aquelas típicas do FUNTEC, no sentido de um programa de natureza especial e administrado segundo normas próprias.

Convém referir-se que o Banco do Nordeste do Brasil-BNB e o Banco de Desenvolvimento do Estado de São Paulo-BADESP, este com o apoio da FINEP, já iniciaram programas de financiamento de pesquisas de interesse, principalmente, de empresas privadas brasileiras, ampliando, destarte, a atuação do BNDE e da FINEP, neste setor. Prevê-se, na vigência do II PBDCT, o aprofundamento desta tendência, com a incorporação de outras agências de fomento econômico ao esquema.

Vale, por fim, assinalar, no quadro institucional para o desenvolvimento científico e tecnológico, a contribuição do pesquisador brasileiro às atividades do SNDCT e ao principal instrumento de orientação das mesmas - o PBDCT. Indicou-se, anteriormente, a participação da comunidade científica no $\mathrm{CNPq}$, onde se faz representar no seu Conselho Científico e Tecnológico-CCT, de que são membros pesquisadores destacados nos diversos campos da Ciência e da Tecnologia, e também por intermédio da Academia Brasileira de Ciências-ABC.

Com relação à Academia, é preocupação governamental utilizar com mais freqüência e intensidade o seu aconselhamento no trato de questôes de relevo 
em política científica e em programas específicos, bem assim na discussão e efetivação de acordos de cooperação científica com o exterior. E prosseguirá na concessão de recursos financeiros para a execução de seus próprios programas de pesquisas, como já o faz. A fim de que se concretize a contribuição da Academia, segundo as linhas indicadas, é preciso que adquira melhores condiçôes no tocante à infra-estrutura técnico-científica e administrativa, garantindo-se-lhe para tanto o concurso financeiro governamental.

Implantado o Sistema Nacional de Desenvolvimento Científico e Tecnológico na concepção fixada nos atos legais citados, segundo as diretrizes enunciadas, obtida a coordenação desejada entre os seus integrantes, e fortalecido o seu órgão central - $\mathrm{CNPq}$ - é de prever-se a consecução eficiente dos objetivos do II PBDCT, em particular o objetivo central de transformar os investimentos nacionais em ciência e tecnologia num instrumento real de desenvolvimento, que se deve apoiar no fortalecimento da capacidade tecnológica da empresa nacional. 